\title{
Dodging Scylla and Charybdis
}

\author{
Robert D. B. Jaquiss, MD
}

\author{
$\overline{\text { From Pediatric }}$ and Congenital Heart Surgery, Children's Medical Center/UT Southwestern Medical Center, \\ Dallas, Tex. \\ Disclosures: Author has nothing to disclose with regard to commercial support. \\ Received for publication Feb 26, 2017; accepted for publication March 2, 2017; available ahead of print April 7, \\ 2017. \\ Address for reprints: Robert D. B. Jaquiss, MD, Children's Medical Center/UT Southwestern Medical Center, \\ 1935 Medical District Drive, Suite B3622, Dallas, TX 75235 (E-mail: Robert.Jaquiss@ UTSouthwestern.edu). \\ J Thorac Cardiovasc Surg 2017; 153:1507-8 \\ $0022-5223 / \$ 36.00$ \\ Copyright (c) 2017 by The American Association for Thoracic Surgery \\ http://dx.doi.org/10.1016/j.jtcvs.2017.03.005
}

The overview of the vexing problems of thrombosis and bleeding in patients supported with ventricular assist devices (VADs) by Massicotte and colleagues ${ }^{1}$ is timely and welcome, with its particular focus on these issues in children with VADs. In much of clinical medicine, the aphorism "it's good to be young," which is likely a paraphrase of an observation by the noted sage Melvin Brooks $^{2}$ in The History of the World (Part I), is certainly true. A notable exception is in the arena of mechanical circulatory support (MCS), because children with VADs are more likely to experience pump thrombosis, systemic thromboembolism, and bleeding than their adult counterparts. For those working in the area of pediatric MCS, clear exposition of the 3 types of risk factors for bleeding and thrombosis by Massicotte and colleagues-patient factors, management factors, and pump factors-serves to focus an investigation that will be foundational for improved outcomes.

We must identify patient attributes that place them at increased risk of bleeding or thrombosis. Some or even many of these attributes may not be modifiable. However, elucidation of the mechanisms of interindividual variability in susceptibility to clotting or bleeding, which may be disease specific, genetic, or both, is necessary to permit prophylaxis tailored to the individual, rather than the one size fits all approach we now apply by default. If our patients are different, we must treat them differently.

In the realm of pump design, better bearings, better surfaces, better rotors, better drivelines, and many other "betters" are on the horizon. However, the timeline for the introduction of modifications or completely novel designs is long, and the expense of development is staggering. The history of VADs includes stories of great pumps doomed by a dearth of venture capital and corporate decisions that are simultaneously economically rational and medically disappointing. As in many other areas of the abutment of medicine and business, the mantra "no margin, no mission" is an ever-present reality for biomedical engineers, surgeons, cardiologists, and company leaders who

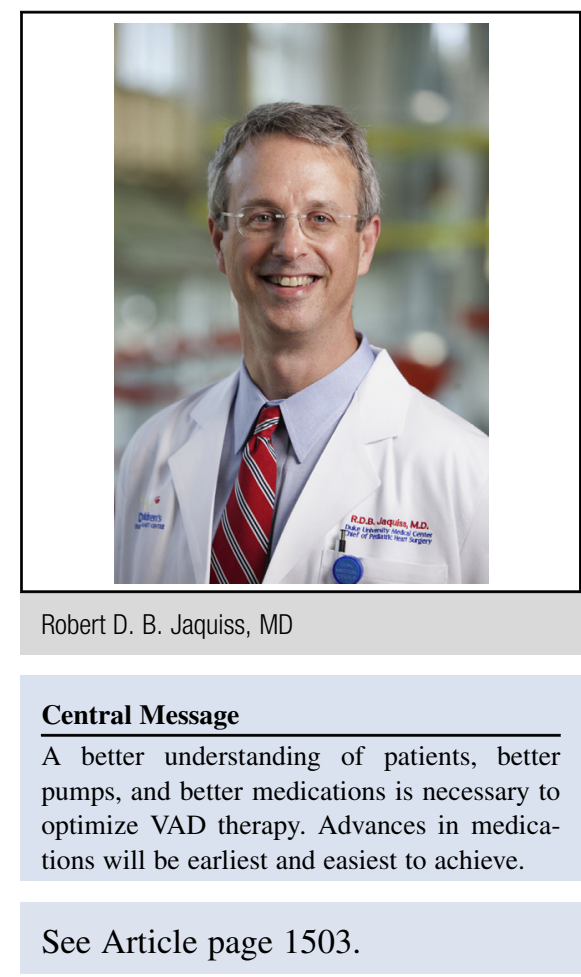

might contemplate stepping into the world of MCS. Because the number of children who might benefit from durable VADs is (happily) so small, the opportunity for margin likewise is relatively tiny. As a partial solution to this conundrum, the Pumps for Kids, Infants, and Neonates (PumpKIN) project is now nearing clinical trials. ${ }^{3}$

Perhaps the area of greatest promise is in the management of the patient and pump interaction. We have at hand a better understanding of the complexities of coagulation and fibrinolysis than ever before. We have new and presumably safer medications for anticoagulation, targeting both protein and cellular components of the process. We have better and more reliable means of assessing the impact of these drugs that should permit us to avoid "overshooting." Perhaps most important, anticoagulation and avoidance of bleeding are crucial aspects of management of an enormous number of patients. Indeed, the market for anticoagulant medications is estimated to be at least $\$ 9$ billion in $2016 .{ }^{4}$ We are likely to have better pills sooner than better pumps.

\section{References}

1. Massicotte P, Snyder T, Stulak J, Kreuziger LB. Ventricular assist device thrombosis: mind your P's \& Q's-pumps, patients, and pills. J Thorac Cardiovasc Surg. 2017;153:1503-6. 
2. The History of the World (Part I) [film]. Brooks M, director. 20th Century Fox; 1981.

3. Baldwin JT, Adachi I, Teal J, Almond CA, Jaquiss RD, Massicotte MP, et al. Closing in on the PumpKIN Trial of the Jarvik 2015 ventricular assist device. Semin Thorac Cardiovasc Surg Pediatr Card Surg Annu. 2017;20: 9-15.

4. Melnikova I. The anticoagulants market. Nat Rev Drug Discov. 2009;8: 353-4. 